\title{
Offshore platforms survivability to underwater explosions: part I
}

\author{
A. A. Motta ${ }^{1}$, E. A. P. Silva ${ }^{2}$, N. F. F. Ebecken ${ }^{2}$ \& T. A. Netto ${ }^{2}$

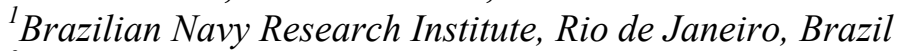 \\ ${ }^{2}$ Federal University of Rio de Janeiro, Rio de Janeiro, Brazil
}

\begin{abstract}
Recent developments in the Brazilian oil industry led to the necessity to conduct offshore platforms underwater explosions (undex) survivability studies. The ongoing research has been segmented in parts, including theoretical and experimental correlated studies. Part of this study involves computer simulation, and, therefore, the necessary validation of the developed models used in such simulations. The existence of benchmark problems helped to establish a guideline to be followed in the study of underwater explosions effects on structural elements and simple and well-controlled experiments are being conducted to be used to calibrate the computer models.

In this work, one of these benchmark problems is presented, along with its experimental implementation: a submerged aluminum cylinder submitted to the undex effects. This problem was proposed by Kwon and Fox in 1993. Results will be collected for the direct shockwave load, the bubble-produced shockwave load, and for both, although the primary interest relies on the shockwave effects. Keywords: underwater explosion, offshore platforms, simulation, survivability.
\end{abstract}

\section{Introduction}

The underwater explosions (undex) terminal effects on semi-submerged steel structures, such as offshore platforms, is a very complex problem, in which individual parts failure can lead to buoyancy or stability problems that can result, in extreme cases, in the loss a platform or in irreversible environmental damage. Since the cost scale in this segment is in order of millions of US dollars, the savings are obvious, and it is imperative, thus, to understand how undex can 
affect these intricate structures and how design modifications can be introduced in order to improve their survivability probability. This problem was presented in [2].

The Submarine Technology Laboratory of the Federal University of Rio de Janeiro started the study of such phenomenon. General guidelines were established based on the available information in the literature and recent developments in current related research. It was decided that the starting point of this study would be on-site small-scale undex experiments, which are currently under development. A tank has been built and the necessary instrumentation is being assembled to perform the tests, similar to available benchmark problems, which are to be conducted in conjunction with computer simulation using Abaqus [3], providing validation material.

In this work, the problem presented in reference 1 is outlined, and its current experimental implementation is presented. Although there are no results available to be presented at this time, it is expected that important data will result from it, allowing the research to move on to more elaborate problems.

\section{Underwater explosions and exponential approximation}

Underwater explosions and their effects on submerged structures were approached in [2]. When an undex happen, a shockwave is instantaneously produced, spreading in all directions. The resulting detonation products form a bubble that pulses, expanding and contracting, while moving toward the surface, and emitting a pressure pulse every time there is an inversion from expansion to contraction and vice-versa. Detailed information on undex and underwater shockwaves are given by Cole [4] and other studies, [5-11], among many other references available in the literature.

As shown in [2], the exponential approximation is widely accepted to represent the shockwave produced in an undex. Various models have been proposed by different authors, all leading to very similar results. In this approximation, the shockwave is represented by an impulse (in which the amplitude is distance-dependent) with exponential decay in time, according to:

where:

$$
\mathrm{P}(\mathrm{t})=\mathrm{P}_{\text {máx }} * \mathrm{e}^{-(\mathrm{t} / \tau)} \quad[\mathrm{Pa}]
$$

$$
\begin{gathered}
\mathrm{P}_{\text {máx }}=\mathrm{K} 1 *\left(\mathrm{~W}^{1 / 3} / \mathrm{d}\right) * \mathrm{~A} 1[\mathrm{~Pa}] \\
\tau=\mathrm{K} 2 * \mathrm{~W}^{1 / 3} *\left(\mathrm{~W}^{1 / 3} / \mathrm{d}\right) * \mathrm{~A} 2 \quad[\mathrm{~s}]
\end{gathered}
$$

$\mathrm{W}$ - is the explosive mass, in TNT-equivalent

$\tau$ - time constant

$\mathrm{d}$ - distance from the explosion source

$\mathrm{K} 1, \mathrm{~K} 2, \mathrm{~A} 1, \mathrm{~A} 2$ - parameters suggested by the author

Models have been introduced for various types of explosives and media, and the one adopted in this work was the model presented by Felippa et al [5] and Shin and Geers [6]. 


\section{The reference problem}

The model problem herein presented is derived from the one proposed by Kwon and Fox [1]. In the original problem, a submerged T6061-T6 aluminum cylinder is exposed to the shockwave produced by the detonation by $60 \mathrm{lb}$ of HBX-1, positioned at a $7.62 \mathrm{~m}$ distance from the cylinder surface. The cylinder particulars are: overall length of $1.067 \mathrm{~m}$; outside diameter of $0.305 \mathrm{~m}$; wall thickness of $6.35 \mathrm{~mm}$, and $24.5 \mathrm{~mm}$ thick welded endcaps. The cylinder is suspended horizontally in a $40 \mathrm{~m}$ deep fresh water test quarry, and the cylinder and the explosive charge are both placed at a depth of $3.66 \mathrm{~m}$. These distances were selected so that cavitation and the bubble pulses can be neglected, as well as reflected waves on the quarry walls and on the free surface. The test profile is presented in figure 1.

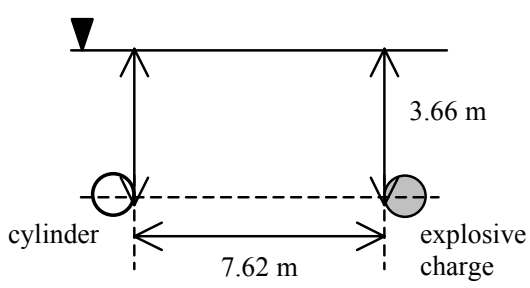

Figure 1: $\quad$ Undex test profile proposed by Kwon and Fox [1].

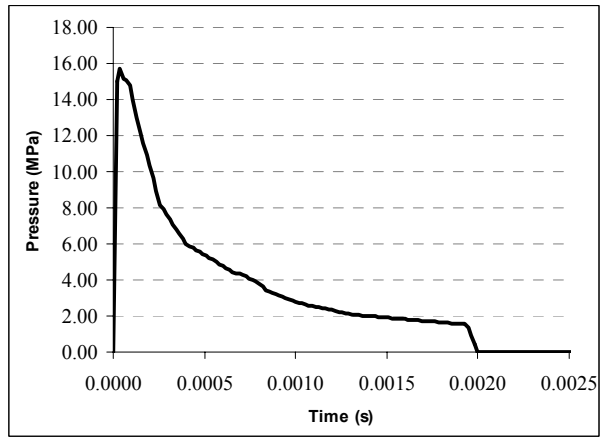

Figure 2: $\quad$ Pressure load curve obtained by Kwon and Fox [1].

A series of strain gauges are placed on the cylinder outer surface and the experimental data is filtered in $2,000 \mathrm{~Hz}$. Two pressure transducers are used to measure the shockwave intensity at $7.62 \mathrm{~m}$ from the source, away from the cylinder for validation purposes. Figure 2 shows the pressure curve as determined by the authors. The cut-off time is set to $2 \mathrm{~ms}$.

In the Abaqus explicit Finite Elements model, the cylinder was discretized in 2,400 quadrilateral shell elements, and the fluid in 45,586 acoustic tetrahedral elements, in a total of 23,337 active degrees of freedom, and the transient 
analyses is run for $8 \mathrm{~ms}$. The outer fluid boundary radius was established as 6 times the cylinder radius, which corresponds to an added mass error of about $6 \%$ for infinite cylinders when compared to an infinite boundary. This is necessary so that the added mass associated with the low-frequency beam bending modes of the cylinder is represented adequately. Table 1 shows the added mass ratio for various fluid boundaries / cylinder radius ratio. Figures 3 and 4 present the complete mesh and more detailed information regarding the cylinder (figure 4(a)) and the fluid (figure 4(b)).

Table 1: $\quad$ Added mass ratio with respect to the radius ratio.

\begin{tabular}{|c|c|}
\hline $\begin{array}{c}\text { Fluid Boundary / } \\
\text { Cylinder Radius Ratio }\end{array}$ & $\begin{array}{c}\text { Added Mass Ratio (External } \\
\text { Boundary/Infinite Domain) }\end{array}$ \\
\hline \hline 1.5 & 2.600 \\
\hline 2.0 & 1.667 \\
\hline 4.0 & 1.133 \\
\hline 6.0 & 1.057 \\
\hline 8.0 & 1.032 \\
\hline 16.0 & 1.008 \\
\hline 24.0 & 1.004 \\
\hline
\end{tabular}

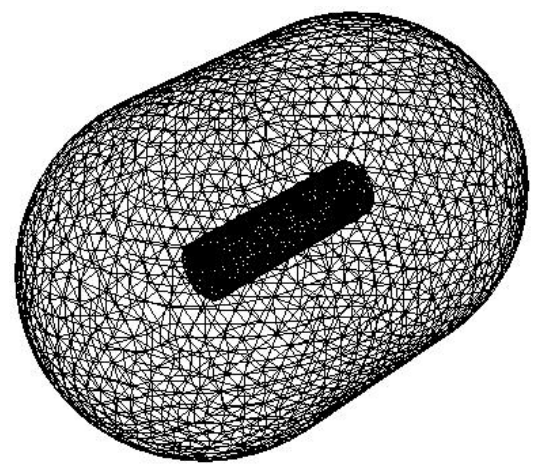

Figure 3: Complete mesh for the Finite Elements implementation for the problem proposed by Kwon and Fox [1].

\section{The ongoing experiment}

The ongoing experiment is very similar to the proposed by Kwon and Fox [1]. The main differences are the cylinder characteristics and material (commercial 2 inches T6061 aluminum pipe), the explosive type and amount, and the distances involved. The media is about the same (still water).

Figure 5 shows the tank under construction where the experiments are to be conducted. Its characteristics and location are such that will allow full control of testing conditions, including the water temperature and salinity. 


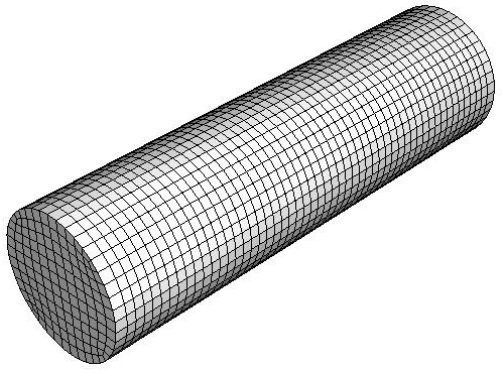

(a)

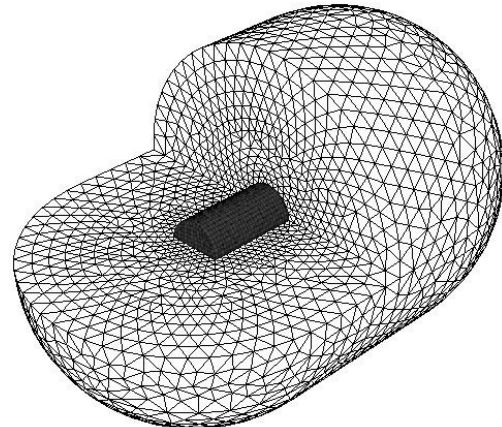

(b)

Figure 4: $\quad$ Mesh details for the Finite Elements implementation of the problem proposed by Kwon and Fox [1], showing the fluid and the cylinder.

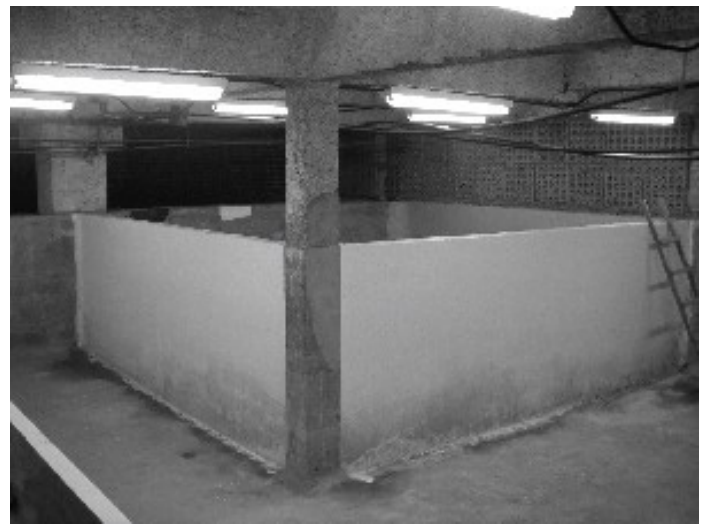

Figure 5: General view of the tank being built to perform the undex experiments.

In figure 6, a general schematics view of the tank is presented. The water mass depth will be $1500 \mathrm{~mm}$, and the aluminum tube, the explosive charge (in the center of the tank), and the transducers are to be positioned in a $750 \mathrm{~mm}$ deep horizontal plane (this will maximize the time for the reflected waves to reach the target, to be set as cut-off time for the experiments).

For this small-scale experiment, charges up to $10 \mathrm{~g}$ are to be used, positioned from 200 to $700 \mathrm{~mm}$ away from the $1500 \mathrm{~mm}$ aluminum air-filled cylinder. The cylinder ends will be welded to thick plates that will be fixed in an "inertial" device, as sketched in figure 7 , to ensure that they will be fully constrained.

\section{Expected results and comments}

As long as the cylinder does not collapse, it is of interest to know its residual strain. Figure 8 presents the accumulated equivalent plastic strains (PEEQ) for the reference problem, as simulated with Abaqus. 

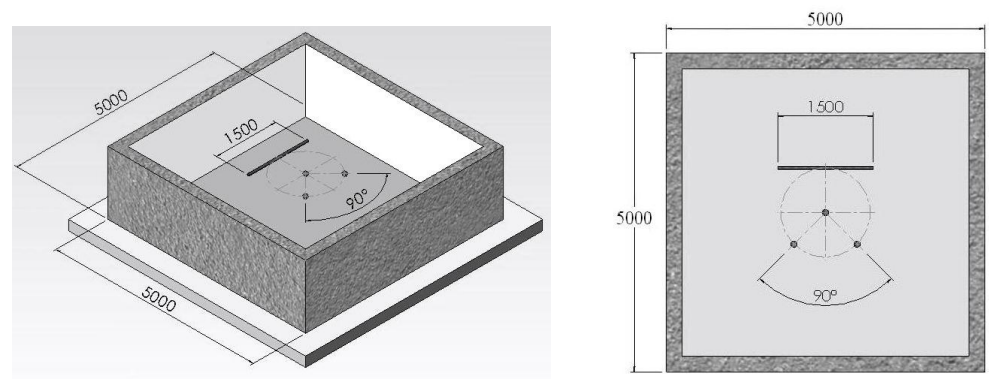

Figure 6: General schematics of the tank being built to perform the undex experiments. The aluminum tube, the explosive charge (in the center of the tank), and the transducers are to be positioned as shown, at half the depth of the water mass.

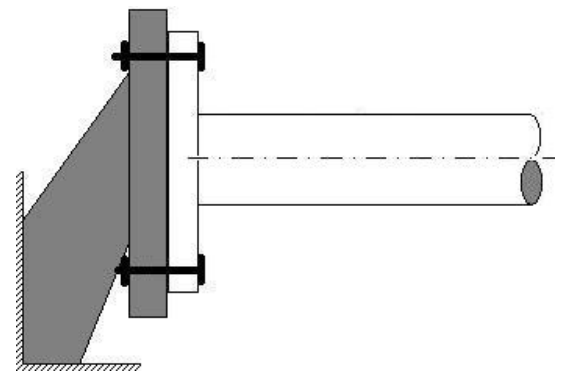

Figure 7: The cylinder ends are to be welded to thick plates that will be mounted in an "inertial" device.

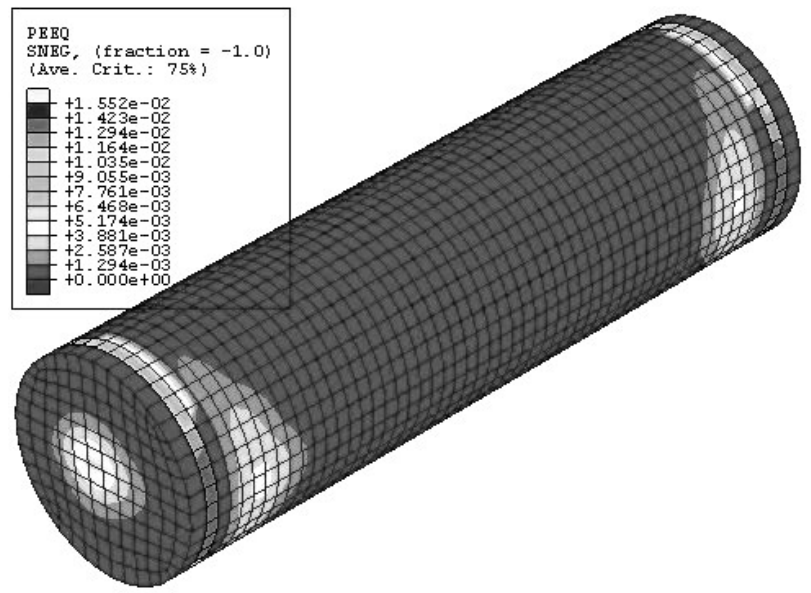

Figure 8: The accumulated equivalent plastic strains (PEEQ) for the reference problem, as simulated with Abaqus. 
It is noticeable that important information can be obtained from the numerical simulation, and Abaqus has shown to be suited for this purpose. The experiments outcome will be used to validate the simulation and, hopefully, while providing new insights about the phenomenon, they will point in the next step direction, where more complex models will be used to provide further information, and so on.

\section{Final remarks}

Structural elements response to underwater explosions are being studied to provide insight to the more complex problem of how these impulsive loads affect offshore platforms. An environment to perform real experiments is under construction, and small-scale tests will be used along with numerical analysis, starting from simple configurations and following into more complex problems and steps are concluded.

It is expected to obtain, from this study, data enough to allow the introduction of design modifications for new platforms to increase their survivability chances if exposed to such loads, as well as the elaboration of contingency plans for platforms already in use and for which modifications are not feasible.

\section{References}

[1] Kwon, K. W., and P. K. Fox, "Underwater Shock Response of a Cylinder Subjected to a Side-On Explosion," Computers and Structures, Vol. 48, No. 4, 1993.

[2] Ballistics studies applied to offshore platforms, Second International Conference on Computational Ballistics, eds. C. A. Brebbia, V. SanchezGalvez, A.A. Motta, and C. E. Anderson, WIT Press: Southampton and Boston, pp. 371-380, 2005.

[3] Abaqus v.6.5, Abaqus, Inc, (http://www.abaqus.com).

[4] Cole, R. H., Underwater Explosions, Princeton University Press: Princeton, 1948.

[5] Felippa, C. A., Geers, T. L. and DeRuntz, J. A., The Underwater Shock Analysis Code: A Reference Manual, Lockheed Palo Alto Research Laboratory, Palo Alto, 1980.

[6] Shin, Y. S. and Geers, T. L., Response of Marine Structures to Underwater Explosions, Short Course, 1993.

[7] Shin, Y. S., Underwater Explosion Research, Volume I - The Shock Wave, Office of Naval Research, US Department of the Navy, 1950.

[8] Shin, Y. S., Application of the USA Code to Underwater Shock Problems, Shock and Vibration Information Analysis Center, 1997.

[9] Shin, Y. S., Experimental Study of Underwater Explosion Phenomena, NDRC, AD 268.905, Vol. 8.

[10] Motta, A. A., Underwater explosive charges optimization with respect to their terminal effects on submerged steel structures, Dissertation, Federal University of Rio de Janeiro, Rio de Janeiro, 2004. 
130 Computational Ballistics III

[11] Motta, A. A. and Ebecken, N. F. F, Steel structures optimization to resist underwater shockwaves - explosive charges optimization, Structures Under Shock and Impact VIII, eds. N. Jones and C. A. Brebbia, WIT Press: Southampton and Boston, pp. 121-128, 2004. 